$\begin{array}{llllllllllllllll}\text { A C T A } & \text { C H E M I C A } & \text { S C A N D I N A V I C A } 27 & \text { (1 } 973) & 2945-2954\end{array}$

\title{
The Crystal Structure of 1,4-Ethyleno-2,8-dihydroxy-2,4,6,8- tetramethyl-octahydronaphthal-5-en-3,7-dione
}

\author{
BENGT KARLSSON, ANNE-MARIE PILOTTI \\ and ANNE.CHARLOTTE WIEHAGER \\ Institute of Inorganic and Physical Chemistry, University of Stockholm, S-104 05 Stockholm 50, \\ Sweden
}

The crystal structure of 1,4-ethyleno-2,8-dihydroxy-2,4,6,8-tetramethyl-octahydronaphthal-5-en-3,7-dione, $\mathrm{C}_{16} \mathrm{H}_{20} \mathrm{O}_{4}$, has been determined by three-dimensional single crystal $\mathrm{X}$-ray diffraction meth. ods. The monoclinic unit cell, $P 2_{1} / c$, has lattice parameters $a=8.470$, $b=12.080, c=14.995 \AA, \beta=108.69^{\circ}$. The intensities of 2804 independent reflexions were measured by using the $\theta-2 \theta$ scan mode with a Siemens automatic diffractometer and monochromatized $\mathrm{Cu} K \alpha$ radiation. The structure was solved by direct methods and refined to an $R$ value of 0.066 for 2076 observed independent reflexions.

The compound is a Diels-Alder dimer of 2,6-dimethyl-o-quinol obtained by periodate oxidation of 2,6-dimethylphenol. The rather strained structure has $\mathrm{C}\left(s p^{3}\right)-\mathrm{C}\left(s p^{3}\right)$ bond lengths of 1.589 and 1.554 $\AA$, respectively, for the bonds $C(4)-C(4 a)$ and $C(4 a)-C(8 a)$.

Oxidation of certain xylenols with sodium periodate results in the formation of $o$-quinols which undergo Diels-Alder dimerisation to yield substituted 1,4ethylenonaphthalenes. Several isomeric dimers can arise but usually only one is observed. The steric orientation of these substituted 1,4-ethylenonaphthalenes have been discussed by Adler et al. ${ }^{1,2}$ and structures have been proposed on the basis of chemical and spectral evidence as well as from considerations of steric requirements.

An X-ray analysis of the title compound has been undertaken as part of a program concerning crystal structure studies of Diels-Alder dimerisation of $o$-quinols.

\section{EXPERIMENTAL}

Crystal data from $\mathrm{X}$-ray photographs and diffractometer measurements are summarized in Table 1. One molecule constitutes the asymmetric unit. Intensity data were collected on a Siemens four circle diffractometer with graphite-monochromatized $\mathrm{CuK \alpha}$ radiation by a $\theta-2 \theta$ scan technique in which the scan width was 150 steps of $0.01^{\circ}$ in

Acta Chem. Scand. 27 (1973) No. 8 
$\theta$ and $0.02^{\circ}$ in $2 \theta$, at 0.6 sec per step. The reflexions were measured twice. Stationary background counts were taken for 90 sec at each end of the scan. By this method 2804 reflexions were measured out to $\theta=70^{\circ}$. The net intensities, $I_{\text {net }}$, and their estimated standard deviations, $\sigma\left(I_{\text {net }}\right)$, based on counter statistics, were calculated. Only the 2076 most significant reflexions with $\sigma\left(I_{\text {net }}\right) / I_{\text {net }} \leq 0.25$ were used in the subsequent calculations. The data were corrected for Lorentz and polarization factors but no correction for absorption was made. Two irregular crystals of approximate volumes $0.011 \mathrm{~mm}^{3}$ and $0.0053 \mathrm{~mm}^{3}$ were mounted with the $b$ axis coincident with the $\phi$ axis of the diffractometer. The crystals deteriorated in the X-ray beam during the data collection. Three monitor reflexions measured at intervals of 40 reflexions showed a deviation of about $15 \%$ in intensity on both crystals. Individual reflexions were corrected for this loss by fitting a linear function of time to the intensity of the monitor reflexions.

Table 1. Crystallographic data (estimated standard deviations in parentheses).

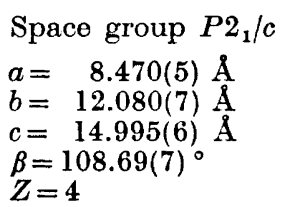

Graphite-monochromatized $\mathrm{CuK} \alpha$ radiation, $1.5418 \AA$.

Chemical formula $\mathrm{C}_{16} \mathrm{H}_{20} \mathrm{O}_{4}$.

Calculated density $1.261 \mathrm{~g} \mathrm{~cm}^{-3}$.

\section{STRUCTURE DETERMINATION AND REFINEMENT}

The absolute scale and the overall temperature factor for calculation of normalized structure factor magnitudes $|E|$ were estimated by Wilson's method. ${ }^{3}$ The structure was solved by use of the MULTAN system. ${ }^{4}$ Four combinations of signs of two reflexions as variables (in addition to three origin determining reflexions) were used to calculate probable phases for the 187 reflexions whose $|E|$ values were $\geq 1.90$. The starting set of phases is given in Table 2. One combination of signs was better than the rest. This solution had a consistency index of 0.79 . The $E$ map of this best $|E|$ set yielded the coordinates of 17 out of the 20 non-hydrogen atoms in the asymmetric unit. The remaining three atoms were located from a difference Fourier synthesis. Introduction of anisotropic thermal parameters for all the non-hydrogen atoms

Table 2. Starting phase set.

\begin{tabular}{|c|c|c|c|c|c|}
\hline \multicolumn{3}{|c|}{$h$} & $\left|E_{h}\right|$ & Starting phase & Correct phase \\
\hline 2 & 3 & -6 & 3.18 & 0 & 0 \\
\hline$\overline{5}$ & 6 & 3 & 3.67 & 0 & 0 \\
\hline 3 & 10 & -6 & 3.12 & 0 & 0 \\
\hline 9 & 5 & -9 & 3.02 & $0, \pi$ & 0 \\
\hline 3 & 8 & -7 & 3.27 & $0, \pi$ & 0 \\
\hline
\end{tabular}


Table 3. Observed and calculated structure amplitudes. The columns contain the index $k, 10\left|F_{\mathrm{o}}\right|$ and $10\left|F_{\mathrm{c}}\right|$. The reflexions marked with an asterisk were not included in the refinement.

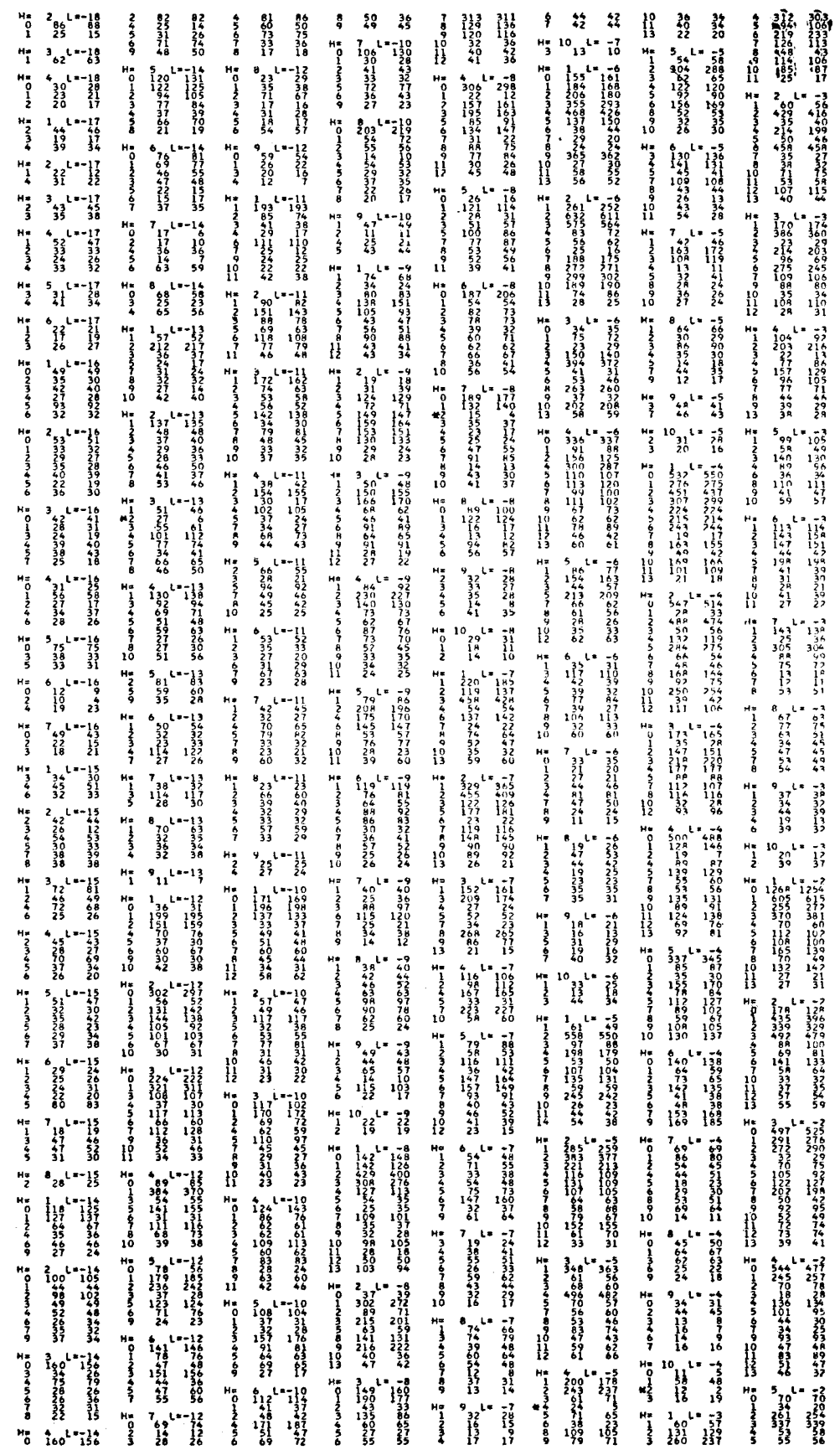


Table 3. Continued.

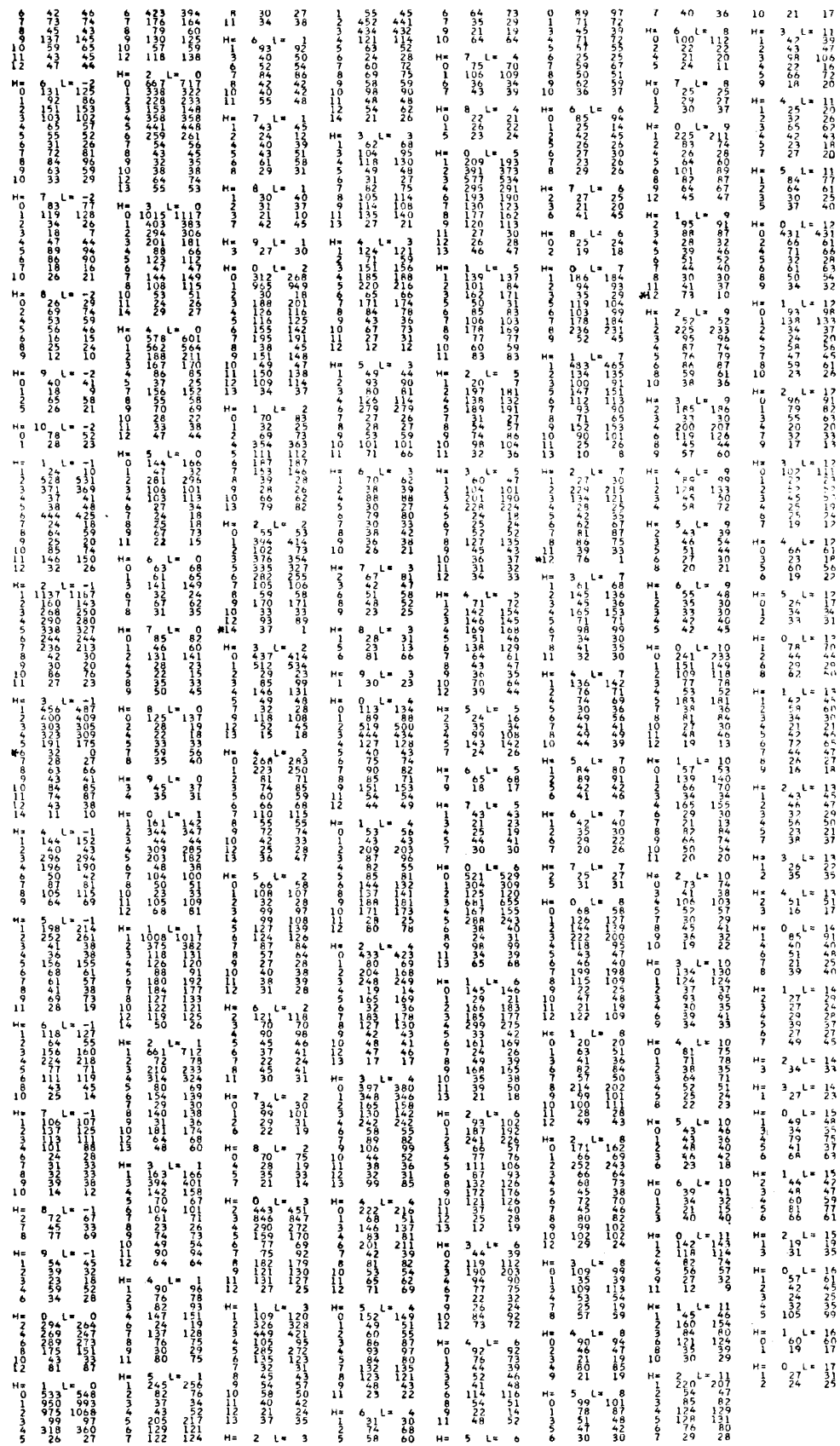

Acta Chem. Scand. 27 (1973) No. 8 
into the fullmatrix least-squares refinement reduced $R$ to 0.117 . The scattering factors of Freeman ${ }^{5}$ were used for all atoms except hydrogens for which the scattering factors were those of Stewart, Davidson and Simpson. ${ }^{6}$ All 20 hydrogen atoms showed well defined peaks in a difference Fourier synthesis. The hydrogens, given fixed isotropic thermal parameters equal to those of their parent atoms, were included in the refinement. 2076 reflexions were used in the refinement and Hughes' 7 weighting procedure with $F_{\text {o,min }}=1.5$ was applied. The $R$ value reduced to 0.066 .

\section{RESULTS}

Observed and calculated structure factors are presented in Table 3, atomic coordinates and thermal parameters in Tables 4 and 5 and bond distances and angles involving the non-hydrogen atoms in Tables 6 and 7. Correction for thermal motion was not applied in the calculation of bond lengths and

Table 4. Positional and anisotropic thermal parameters of the non-hydrogen atoms. The $\beta$-values refer to the temperature factor expression exp $\left[-\left(h^{2} \beta_{11}+k^{2} \beta_{22}+l^{2} \beta_{33}+h k \beta_{12}+h l \beta_{13}+k l \beta_{23}\right)\right]$. Estimated standard deviations are given in parentheses.

\begin{tabular}{|c|c|c|c|c|c|c|c|c|c|}
\hline & $x \times 10^{4}$ & $y \times 10^{4}$ & $z \times 10^{4}$ & $\beta_{11} \times 10^{4}$ & $\beta_{22} \times 10^{4}$ & $\beta_{33} \times 10^{4}$ & $\beta_{12} \times 10^{4}$ & $\beta_{13} \times 10^{4}$ & $\beta_{23} \times 10^{4}$ \\
\hline$C(1)$ & $8992(4)$ & $1867(2)$ & $4475(2)$ & $167(5)$ & $51(2)$ & $35(2)$ & $2(4)$ & $58(4)$ & $8(3)$ \\
\hline $\mathrm{C}(2)$ & $9724(4)$ & $3040(3)$ & $4711(2)$ & $180(5)$ & $59(2)$ & $40(2)$ & $-15(5)$ & $71(4)$ & $-11(3)$ \\
\hline $\mathrm{C}(3)$ & $9523(4)$ & $3603(3)$ & $3759(2)$ & $183(5)$ & $54(2)$ & $48(2)$ & $-21(5)$ & $93(4)$ & $-11(3)$ \\
\hline $\mathrm{C}(4)$ & $8930(4)$ & $2846(2)$ & $2908(2)$ & $195(5)$ & $56(2)$ & $39(2)$ & $-25(5)$ & $88(4)$ & $-3(3)$ \\
\hline $\mathrm{C}(4 \mathrm{a})$ & $7108(4)$ & $2473(3)$ & $2867(2)$ & $156(5)$ & $59(2)$ & $45(2)$ & $42(5)$ & $48(4)$ & $20(3)$ \\
\hline $\mathrm{C}(5)$ & $6504(4)$ & $1664(4)$ & $2067(3)$ & $197(6)$ & $121(4)$ & $40(2)$ & $-63(7)$ & $32(5)$ & $6(4)$ \\
\hline $\mathrm{C}(6)$ & $6203(4)$ & $599(3)$ & $2132(3)$ & $170(6)$ & $102(3)$ & $58(2)$ & $-50(6)$ & $46(5)$ & $-39(4)$ \\
\hline $\mathrm{C}(7)$ & $6296(4)$ & $153(3)$ & $3059(3)$ & $153(5)$ & $66(3)$ & $66(2)$ & $-33(5)$ & $26(5)$ & $-11(3)$ \\
\hline $\mathrm{C}(8)$ & $6079(4)$ & $973(3)$ & $3777(2)$ & $161(5)$ & $86(3)$ & $53(2)$ & $-46(6)$ & $67(5)$ & $11(3)$ \\
\hline$C(8 a)$ & $7158(4)$ & $2015(3)$ & $3844(2)$ & $146(5)$ & $57(2)$ & $46(2)$ & $11(4)$ & $81(4)$ & $-4(3)$ \\
\hline $\mathrm{C}(9)$ & $9983(4)$ & $1294(3)$ & $3929(2)$ & $144(5)$ & $58(2)$ & $55(2)$ & $28(5)$ & $44(4)$ & $-6(3)$ \\
\hline$C(10)$ & $9980(4)$ & $1805(3)$ & $3152(2)$ & $149(5)$ & $73(2)$ & $54(2)$ & $3(5)$ & $86(4)$ & $-34(3)$ \\
\hline $\mathrm{C}(11)$ & $11552(5)$ & $3046(4)$ & $5324(3)$ & $211(7)$ & $89(3)$ & $58(2)$ & $-50(7)$ & $47(6)$ & $-19(4)$ \\
\hline$O(12)$ & $8737(3)$ & $3615(2)$ & $5168(2)$ & $260(5)$ & $74(2)$ & $57(2)$ & $-49(4)$ & $137(4)$ & $-46(2)$ \\
\hline $\mathrm{O}(13)$ & $9757(4)$ & $4580(2)$ & $3695(2)$ & $406(7)$ & $57(2)$ & $64(2)$ & $-88(5)$ & $152(5)$ & $-15(2)$ \\
\hline$C(14)$ & $8996(6)$ & $3429(4)$ & $2018(3)$ & $332(9)$ & $78(3)$ & $49(2)$ & $-64(8)$ & $142(7)$ & $-1(4)$ \\
\hline $\mathrm{C}(15)$ & $5818(8)$ & $-189(5)$ & $1310(4)$ & $321(11)$ & $159(6)$ & $78(3)$ & $-159(12)$ & $80(9)$ & $-97(7)$ \\
\hline$O(16)$ & 6394(4) & $-833(2)$ & $3234(3)$ & $334(7)$ & $76(2)$ & $100(2)$ & $-38(6)$ & $10(6)$ & $-9(3)$ \\
\hline $\mathrm{C}(17)$ & $4239(5)$ & $1303(4)$ & $3468(4)$ & $175(7)$ & $131(4)$ & $113(4)$ & $-57(8)$ & $150(8)$ & $-28(6)$ \\
\hline$O(18)$ & $6508(4)$ & $462(3)$ & $4677(2)$ & $317(6)$ & $122(3)$ & $67(2)$ & $-158(7)$ & $112(5)$ & $34(3)$ \\
\hline
\end{tabular}

angles. Conformationally significant least-squares planes are given in Table 8, and intermolecular distances shorter than $3.8 \AA$ in Table 9. Fig. 1 shows the numbering convention and all bond lengths of the non-hydrogen atoms. Fig. 2 is a perspective view ${ }^{8}$ of the molecule. Fig. 3 is a projection of the crystal structure along the $b$ axis.

Acta Chem. Scand. 27 (1973) No. 8 
Table 5. Positional and isotropic thermal parameters of the hydrogen atoms, with estimated standard deviations in parentheses.

\begin{tabular}{|c|c|c|c|c|}
\hline & $x \times 10^{3}$ & $y \times 10^{3}$ & $z \times 10^{3}$ & $B \times 10^{2} \AA^{2}$ \\
\hline $\mathrm{H}(\mathrm{C} 1)$ & $903(3)$ & $155(3)$ & $500(2)$ & 273 \\
\hline $\mathrm{H}(\mathrm{C} 4 \mathrm{a})$ & $657(4)$ & $302(3)$ & $273(2)$ & 336 \\
\hline $\mathrm{H}(\mathrm{C} 5)$ & $634(4)$ & $194(3)$ & $150(3)$ & 441 \\
\hline H1(C8) & $381(6)$ & $165(4)$ & $289(3)$ & 647 \\
\hline $\mathrm{H} 2$ (C8) & $413(6)$ & $170(4)$ & $397(3)$ & 647 \\
\hline H3(C8) & $350(4)$ & $61(3)$ & $352(2)$ & 647 \\
\hline $\mathrm{H}(\mathrm{C} 8 \mathrm{a})$ & $672(4)$ & $256(3)$ & $409(2)$ & 287 \\
\hline $\mathrm{H}(\mathrm{C} 9)$ & $1054(4)$ & $62(3)$ & $414(2)$ & 331 \\
\hline H(C10) & $1055(4)$ & $154(3)$ & $276(2)$ & 345 \\
\hline H1(C11) & $1194(5)$ & $382(3)$ & $545(3)$ & 467 \\
\hline $\mathrm{H} 2$ (C11) & $1167(5)$ & $267(3)$ & $589(3)$ & 467 \\
\hline H3(C11) & $1220(5)$ & $260(3)$ & $505(3)$ & 467 \\
\hline $\mathrm{H}(\mathrm{O} 12)$ & $924(5)$ & $405(3)$ & $547(3)$ & 391 \\
\hline $\mathrm{Hl}$ (Cl4) & $881(4)$ & $299(3)$ & $154(3)$ & 431 \\
\hline $\mathrm{H} 2(\mathrm{Cl4})$ & $1016(4)$ & $385(3)$ & $213(3)$ & 431 \\
\hline $\mathrm{H} 3$ (Cl4) & $804(5)$ & $392(3)$ & $181(3)$ & 431 \\
\hline $\mathrm{Hl}$ (Cl5) & $589(6)$ & $27(4)$ & $68(3)$ & 678 \\
\hline $\mathrm{H} 2(\mathrm{Cl} 5)$ & $465(6)$ & $-34(4)$ & $118(3)$ & 678 \\
\hline H3(CI5) & $658(6)$ & $-74(4)$ & $143(4)$ & 678 \\
\hline $\mathrm{H}(\mathrm{O} 18)$ & $624(5)$ & $-18(4)$ & $458(3)$ & 544 \\
\hline
\end{tabular}

Table 6. Bond distances $(\AA)$ involving the non-hydrogen atoms, with estimated standard deviations in parentheses.

\begin{tabular}{llll}
\hline$C(1)-C(2)$ & $1.542(4)$ & $C(4 a)-C(5)$ & $1.505(4)$ \\
$C(1)-C(8 a)$ & $1.549(4)$ & $C(4 a)-(8 a)$ & $1.554(4)$ \\
$C(1)-C(9)$ & $1.515(4)$ & $C(5)-C(6)$ & $1.321(5)$ \\
$C(2)-C(3)$ & $1.539(4)$ & $C(6)-C(7)$ & $1.470(4)$ \\
$C(2)-C(11)$ & $1.528(4)$ & $C(6)-C(15)$ & $1.507(6)$ \\
$C(2)-O(12)$ & $1.420(3)$ & $C(7)-C(8)$ & $1.517(4)$ \\
$C(3)-C(4)$ & $1.519(4)$ & $C(7)-O(16)$ & $1.217(4)$ \\
$C(3)-O(13)$ & $1.205(3)$ & $C(8)-C(8 a)$ & $1.540(4)$ \\
$C(4)-C(4 a)$ & $1.589(4)$ & $C(8)-C(17)$ & $1.531(5)$ \\
$C(4)-C(10)$ & $1.517(4)$ & $C(8)-O(18)$ & $1.420(4)$ \\
$C(4)-C(14)$ & $1.526(4)$ & $C(9)-C(10)$ & $1.318(4)$ \\
\hline
\end{tabular}

\section{DISCUSSION}

The structural and conformational features of the dimer are illustrated in Fig. 2. The result is in agreement with the stereochemical considerations discussed by Adler et al. ${ }^{1}$ A rewiew of the theory concerning Diels-Alder dimerisation, in conjunction with results from X-ray structure determinations, has been presented by Karlsson et al. ${ }^{9}$ Most bond lengths in this structure are in agreement with usually observed values. $.^{10} \mathrm{C}(4)-\mathrm{C}(4 \mathrm{a})(1.589 \AA)$ and $\mathrm{C}(4 \mathrm{a})-$ $\mathrm{C}(8 \mathrm{a})(1.554 \AA)$ are, however, significantly longer $(\sim 5 \sigma$ and $\sim 13 \sigma$, respec- 


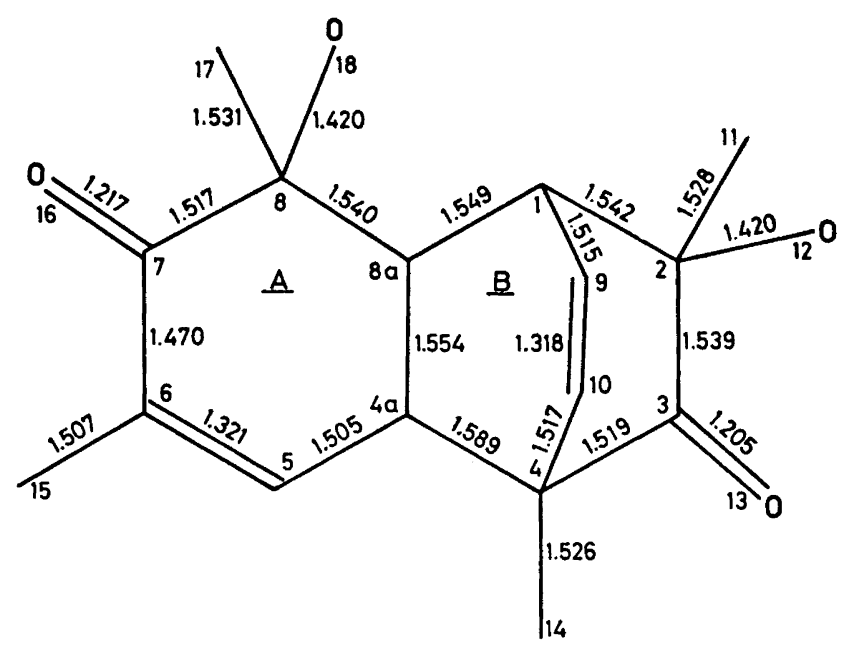

Fig. 1. Bond distances in the molecule

tively) than the average value, $1.536 \AA$, of the other $\mathrm{C}\left(s p^{3}\right)-\mathrm{C}\left(s p^{3}\right)$ bonds in the structure. This is probably due to internal strain in the molecule. Effects of conjugation are apparent in the $\mathrm{C}(6)-\mathrm{C}(7)$ bond adjacent to double bonds. The average value of the $C\left(s p^{2}\right)-C\left(s p^{3}\right)$ bonds is $1.517 \AA ; \sim 4 \sigma$ longer than the accepted value of $1.50 \AA .11$ This can probably be explained by the fact that

Table 7. Bond angles $\left({ }^{\circ}\right)$ involving non-hydrogen atoms, with estimated standard deviations in parentheses.

\begin{tabular}{llll}
\hline & & & \\
$C(2)-C(1)-C(8 a)$ & $106.6(2)$ & $C(5)-C(4 a)-C(8 a)$ & $114.9(3)$ \\
$C(2)-C(1)-C(9)$ & $107.0(3)$ & $C(4 a)-C(5)-C(6)$ & $126.7(3)$ \\
$C(8 a)-C(1)-C(9)$ & $110.1(2)$ & $C(5)-C C(6)-C(7)$ & $118.3(3)$ \\
$C(1)-C(2)-C(3)$ & $106.1(2)$ & $C(5)-C(6)-C(15)$ & $123.4(4)$ \\
$C(1)-C(2)-C(11)$ & $113.5(3)$ & $C(7)-C(6)-C(15)$ & $118.3(4)$ \\
$C(1)-C(2)-O(12)$ & $107.7(3)$ & $C(6)-C(7)-C(8)$ & $116.8(3)$ \\
$C(3)-C(2)-C(11)$ & $110.2(3)$ & $C(6)-C(7)-O(16)$ & $122.8(3)$ \\
$C(3)-C(2)-O(12)$ & $108.9(3)$ & $C(8)-C(7)-O(16)$ & $120.1(3)$ \\
$C(11)-C(2)-O(12)$ & $110.3(3)$ & $C(7)-C(8)-C(8 a)$ & $112.1(3)$ \\
$C(2)-C(3)-C(4)$ & $114.9(3)$ & $C(7)-C(8)-C(17)$ & $107.3(3)$ \\
$C(2)-C(3)-O(13)$ & $122.3(3)$ & $C(7)-C(8)-O(18)$ & $109.8(3)$ \\
$C(4)-C(3)-O(13)$ & $122.7(3)$ & $C(8 a)-C(8)-C(17)$ & $109.4(3)$ \\
$C(3)-C(4)-C(4 a)$ & $105.0(3)$ & $C(8 a)-C(8)-O(18)$ & $109.1(3)$ \\
$C(3)-C(4)-C(10)$ & $106.6(3)$ & $C(17)-C(8)-O(18)$ & $109.1(3)$ \\
$C(3)-C(4)-C(14)$ & $111.2(3)$ & $C(1)-C(8 a)-C(4 a)$ & $109.7(2)$ \\
$C(4 a)-C(4)-C(10)$ & $105.2(2)$ & $C(1)-C(8 a)-C(8)$ & $113.8(3)$ \\
$C(4 a)-C(4)-C(14)$ & $113.8(3)$ & $C(4 a)-C(8 a)-C(8)$ & $113.1(3)$ \\
$C(10)-C(4)-C(14)$ & $114.2(3)$ & $C(1)-C(9)-C(10)$ & $114.8(3)$ \\
$C(4)-C(4 a)-C(5)$ & $107.1(3)$ & $C(4)-C(10)-C(9)$ & $115.9(3)$ \\
$C(4)-C(4 a)-C(8 a)$ & $109.3(2)$ & & \\
\hline
\end{tabular}

Acta Chem. Scand. 27 (1973) No. 8 
Table 8. Least-squares planes and deviations. The planes are described in terms of axes $(m, n, p)$ having $m\left\|a^{*}, n\right\| b$ and $p \| c$. The atoms indicated with asterisks were omitted from the calculations of the least-squares planes. Deviation in $\AA$.

\begin{tabular}{|c|c|c|c|c|c|c|c|}
\hline \multicolumn{2}{|c|}{ Plane $A^{a}$} & \multicolumn{2}{|c|}{ Plane $\mathrm{Bl}^{b}$} & \multicolumn{2}{|c|}{ Plane $\mathrm{B} 2^{c}$} & \multicolumn{2}{|c|}{ Plane $\mathrm{B}^{d}$} \\
\hline Atom & Deviation & Atom & Deviation & Atom & Deviation & Atom & Deviation \\
\hline$C(4 a)$ & 0.035 & $\mathrm{C}(1)^{*}$ & 0.786 & $C(1)^{*}$ & -0.736 & $\mathrm{C}(1)^{*}$ & 0.627 \\
\hline $\mathrm{C}(5)$ & -0.035 & $\mathrm{C}(2)$ & 0.048 & $\mathrm{C}(2)$ & 0.034 & $\mathrm{C}(4)^{*}$ & 0.752 \\
\hline$C(6)$ & 0.015 & $\mathrm{C}(3)$ & -0.048 & $\mathrm{C}(3)$ & -0.035 & $C(4 a)$ & -0.040 \\
\hline$C(7)$ & 0.004 & $\mathrm{C}(4)^{*}$ & 0.735 & $\mathrm{C}(4)^{*}$ & -0.628 & $\mathrm{C}(8 \mathrm{a})$ & 0.040 \\
\hline $\mathrm{C}(8)^{*}$ & -0.575 & $C(4 a)$ & 0.048 & $\mathrm{C}(9)$ & -0.040 & $\mathrm{C}(9)$ & -0.047 \\
\hline$C(8 a)$ & -0.018 & $\mathrm{C}(8 \mathrm{a})$ & -0.048 & $\mathrm{C}(10)$ & 0.040 & $\mathrm{C}(10)$ & 0.047 \\
\hline
\end{tabular}

$a$ Plane A : $0.9584 m-0.2400 n-0.1545 p=4.3480$.

$b$ Plane B1: $0.9911 m+0.1331 n-0.0004 p=8.1852$.

$c$ Plane B2: $0.3899 m+0.8450 n+0.3660 p=5.6554$.

$d$ Plane B3: $0.5878 m-0.7254 n-0.3582 p=0.2892$.

Table 9. Intermolecular distances $(\AA)$ shorter than $3.8 \AA$, with estimated standard deviations in parentheses.

\begin{tabular}{|c|c|c|c|}
\hline Superscript & $\begin{array}{l}\text { Code for symmetry } \\
\text { Coordinates }\end{array}$ & $\begin{array}{l}\text { related atoms. } \\
\text { Superscript }\end{array}$ & Coordinates \\
\hline $\begin{array}{l}\text { none } \\
\text { i } \\
\text { ii } \\
\text { iii } \\
\text { iv } \\
\end{array}$ & $\begin{array}{l}\quad x, y, z \\
1+x, y, z \\
1-x,-y,-z \\
1-x,-y, 1-z \\
2-x,-y, 1-z\end{array}$ & $\begin{array}{l}\text { v } \\
\text { vi } \\
\text { vii } \\
\text { viii }\end{array}$ & $\begin{array}{l}2-x, 1-y, 1-z \\
\quad x, \frac{1}{2}-y,-\frac{1}{2}+z \\
1-x, \frac{1}{2}+y, \frac{1}{2}-z \\
2-x, \frac{1}{2}+y, \frac{1}{2}-z\end{array}$ \\
\hline $\begin{array}{l}\mathrm{C}(10)-\mathrm{C}\left(17^{\mathrm{i}}\right) \\
C(15)-C\left(15^{\mathrm{ii}}\right) \\
C(17)-O\left(18^{\mathrm{iii}}\right) \\
O(18)-O\left(18^{\mathrm{iii}}\right) \\
C(9)-O\left(18^{\mathrm{iv}}\right) \\
C(11)-O\left(16^{\mathrm{iv}}\right) \\
C(2)-O\left(13^{\mathrm{v}}\right)\end{array}$ & $\begin{array}{l}3.537(5) \\
3.754(10) \\
3.716(6) \\
3.209(6) \\
3.706(4) \\
3.529(5) \\
3.675(3)\end{array}$ & $\begin{array}{l}C(11)-O\left(13^{\mathrm{v}}\right) \\
O(12)-O\left(13^{\mathrm{v}}\right) \\
C(14)-O\left(12^{\mathrm{vi}}\right) \\
C(14)-O\left(18^{\mathrm{vi}}\right) \\
C(4 a)-O\left(16^{\mathrm{vii}}\right) \\
O(13)-C\left(15^{\mathrm{vii}}\right.\end{array}$ & $\begin{array}{l}3.559(4) \\
2.811(3) \\
3.667(4) \\
3.719(4) \\
3.547(4) \\
3.761(7)\end{array}$ \\
\hline
\end{tabular}

many of the bonds involve a highly substituted carbon atom. The $\mathrm{C}-\mathrm{H}$ bond distances range from 0.73 to $1.11 \AA$, mean value $0.92 \AA$, in good agreement with values found in some precisely determined $\mathrm{X}$-ray structures. ${ }^{6}$ The best plane for the ring $A$ (Fig. 1) contains the atoms $C(4 a), C(5), C(6), C(7)$, and $\mathrm{C}(8 \mathrm{a})$ which are coplanar within $\pm 0.035 \AA$. Atom $\mathrm{C}(8)$ deviates by $0.575 \AA$ from the plane (Table 8 ). The rather strained ring system $B$ consists of three boat-shaped rings, for which least-squares planes and deviations are given in Table 8 . The $A$ ring and the $B$ ring system are connected in accordance with the endo rule. ${ }^{12}$ 
Fig. 2. A perspective view of the molecule.

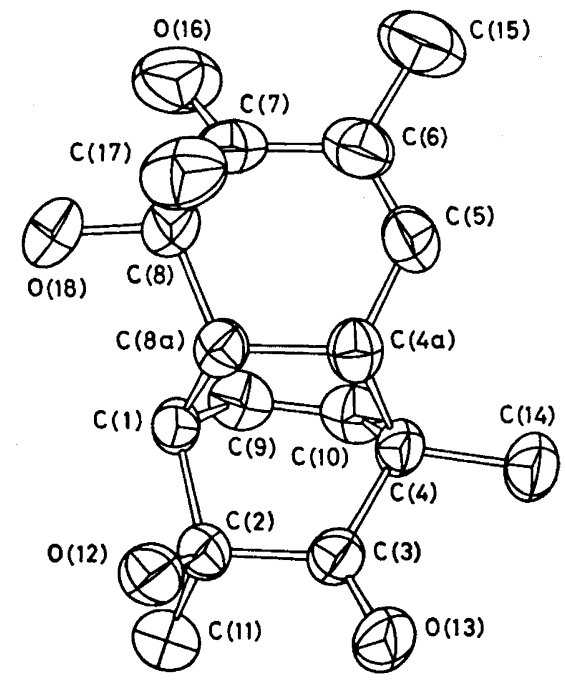

An interaction, within the range of a possible intramolecular hydrogen bond, is observed between the hydroxyl group (18) and the ketone (16). The $\mathrm{O}(16) \ldots \mathrm{H}(\mathrm{O18})$ and $\mathrm{O}(16) \ldots \mathrm{O}(18)$ distances are 2.211 and $2.646 \AA$, respectively, and the $\mathrm{O}(16) \cdots \mathrm{H}(\mathrm{O} 18)-\mathrm{O}(18)$ angle is $113.9^{\circ}$. The packing arrangement of the crystal viewed along the $b$ axis is shown in Fig. 3. Those pairs of molecules related to each other by centers of symmetry at $0,0,0$ and $0, \frac{1}{2}, \frac{1}{2}$ form hydrogen bonded dimers. The $\mathrm{O}\left(13^{\mathrm{v}}\right) \ldots \mathrm{H}(\mathrm{O} 12)$ distance is $2.091 \AA$ and the $\mathrm{O}(12)-\mathrm{H}(\mathrm{O} 12) \ldots \mathrm{O}\left(13^{\mathrm{v}}\right)$ angle is $169.4^{\circ}$. The intermolecular distances between the hydrogen bonded dimers are all longer than the sum of the van der Waals radii as shown in Table 9.

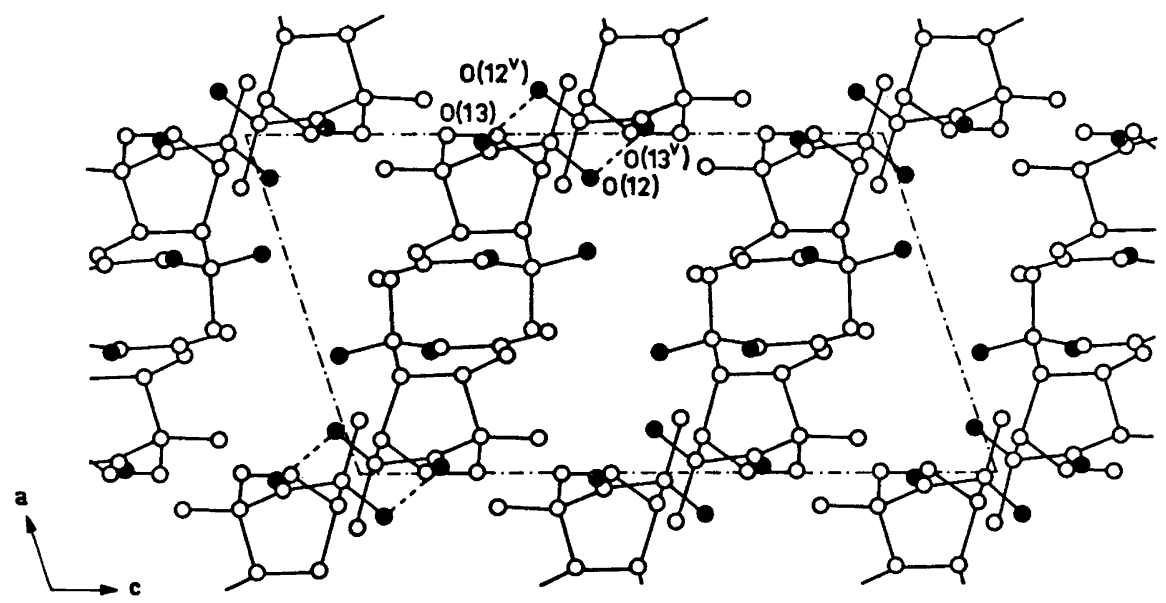

Fig. 3. Projection of the unit cell looking down the $b$ axis. The dotted lines are hydrogen bonds. $O$ carbon; - oxygen. 
This investigation has received financial support from the Tri-Centennial Fund of the Bank of Sweden and from the Swedish Natural Science Research Council.

The authors are indebted to Professor Peder Kierkegaard for his encouraging interest in this work and for the facilities placed at their disposal. Thanks are due to Dr. Bengt Lindgren for the supply of crystals used in the work and for valuable comments. Dr. Ake Pilotti is also thanked for valuable discussions and Dr. Don Koenig for his correction of the English of this paper.

\title{
REFERENCES
}

1. Adler, E., Brasen, S. and Miyake, H. Acta Chem. Scand. 25 (1971) 2055.

2. Adler, E. and Holmberg, K. Acta Chem. Scand. 25 (1971) 2775.

3. Wilson, A. J. C. Nature, 150 (1942) 151.

4. Germain, G., Main, P. and Woolfson, H. M. Acta Cryst. B 26 (1970) 274.

5. Freeman, A. J. Acta Cryst. 12 (1959) 261.

6. Stewart, R. F., Davidson, E. R. and Simpson, W. T. J. Chem. Phys. 42 (1965) 3175.

7. Hughes, E. W. J. Am. Chem. Soc. 63 (1941) 1737.

8. Johnson, C. K. ORTEP Report ORNL-3794 (1965), Oak Ridge National Laboratory, Oak Ridge, Tennessee.

9. Karlsson, B., Kierkegaard, P., Pilotti, A.-M., Wiehager, A.-C. and Lindgren, B. Acta Chem. Scand. 27 (1973) 1428.

10. Sutton, L. E. Tables of Interatomic Distances and Configuration in Molecules and Ions (1965), Supplement 1956-1959. London: The Chemical Society.

11. Lide, D. R. Tetrahedron 17 (1962) 125.

12. Martin, J. G. and Hill, R. K. Chem. Rev. 61 (1961) 537.

Received April 18, 1973.

\author{
KEMISK BIBLIOTEK \\ Den kgl. Veterinær - og Landbohøjskole
}

Acta Chem. Scand. 27 (1973) No. 8 